\title{
Analysis of Hydrogen Trapping by Gaussian Distribution for Normalized Carbon Steels
}

\author{
Yutaka TSUCHIDA* \\ Department of Mechanical Engineering, School of Engineering, Daido University, Takiharu-cho 10-3, Minami-ku, Nagoya, Aichi, \\ 457-8530 Japan.
}

(Received on July 5, 2013; accepted on October 8, 2013)

\begin{abstract}
For the basis of understanding hydrogen embrittlement, hydrogen thermal desorption curves are subjected to the analysis for making clear the kinds and amounts of traps in normalized carbon steels that are composed of ferrite and pearlite. While the theoretical desorption curves should be analyzed basically by non-symmetrical curves such as obtained by Kissinger equation, the measured curves are also deformed and approach to symmetrical form. Actually they are successfully fitted by combination of two symmetrical Gaussians; one is desorption from dislocation trap and the other is from grain boundary trap. Applying this method to different heats of JIS S45C steel, grain boundary trap of high phosphorus content shifts to higher temperature side, suggesting that hydrogen trap is enhanced by phosphorus segregation along grain boundary. An increase in cathodic current density causes more hydrogen partition to grain boundary. Analysis with the use of Gaussian is practical and reasonable to understand the properties of hydrogen traps.
\end{abstract}

KEY WORDS: hydrogen desorption; hydrogen trap; grain boundary; dislocation; gaussian distribution; kissinger equation.

\section{Introduction}

Under the circumstances where hydrogen would enter, the steels are degraded in ductility or strength, leading to the immature fracture. This phenomenon is called hydrogen embrittlement that should be avoided in the design or operation of plants or machines.

Almost all the hydrogen in steels is weakly trapped by nanosized open-volume defects like the lattice defects; dislocation, vacancy, grain boundary, and precipitate/matrix interface. When hydrogen is trapped by these lattice defects, it alters the nature of the lattice defects. This in return affects the deformation behavior or fracture, and causes the degradation in ductility or strength.

For obtaining this important information about lattice defects that would trap hydrogen, researchers can use various devices, such as tritium autoradiography, ${ }^{1)}$ hydrogen microprint technique, ${ }^{2)}$ positron annihilation spectroscopy, ${ }^{3)}$ thermal desorption analysis. ${ }^{4,5)}$ The former two methods are able to determine the location of hydrogen trap in relation microstructures, though they have some difficulty in resolution. Hydrogen thermal desorption analysis measures hydrogen emission from the whole specimen. It is unable to determine directly what kind of microstructure is the trapping site: It should be estimated from the tapping energy via peak temperature. Positron annihilation spectroscopy is sensitive to detect nanosized void, but it cannot identify the

* Corresponding author: E-mail: tsuchida@daido-it.ac.jp

DOI: http://dx.doi.org/10.2355/isijinternational.54.644 kind of defect in correspondence to microstructure; developments ${ }^{6}$ is underway for expanding to local observation.

Among those measurement techniques, hydrogen thermal desorption analysis (TDA) is widely used, where gas chromatograph is utilized. This is originally developed so as to measure the diffusible hydrogen during heating at slow rate. Recently it is frequently used to determine the kind of hydrogen trap site through analyzing the shape and peak temperature of desorption curve. Theoretical curves obtained by McNabb-Foster ${ }^{7-9)}$ equation or Kissinger ${ }^{10)}$ equation are often useful for the ends. There is another successful example where the statistical distribution function of Gaussian was applied to the analysis. ${ }^{11)}$ The quadrupole mass spectrometer is also used instead of gas chromatograph. Recent topic in this field is the development of low temperature TDA, which enables precise desorption measurement from low temperatures (e.g. liquid nitrogen temperature). ${ }^{12)}$

This report tries first to fit hydrogen desorption curve of normalized JIS S45C steel specimen, by use of Kissinger equation under the assumption of hydrogen diffusion in the lattice is fast enough. Then the origin of possible discrepancy of actual data from Kissinger equation is discussed, leading to the applicability of Gaussian distribution for the fitting and separation of peaks. Using this fitting method, the quantitative analysis is reported on the amount and binding energy of traps. 


\section{Experimental Method}

Commercial JIS S45C and JIS S10C rolled round bar stocks (28 $\mathrm{mm}$ in diameter) are used for the study. The chemical compositions (check analysis) are summarized in the Table 1. Steel $45 \mathrm{C}$ has been prepared for this study. Steels $45 \mathrm{~A}$ and $45 \mathrm{~B}$ are examined in the previous study; ${ }^{13,14)}$ steel $10 \mathrm{~A}$ is also used in the other study. ${ }^{15)}$ All the steel bars are normalized at $1123 \mathrm{~K}$ : The volume fractions of lamellar pearlite in $45 \mathrm{~A}$ and $45 \mathrm{~B}$ are almost $50 \%$ and that of $10 \mathrm{~A}$ is about $8 \%$.

These heat treated steel bars are subjected to machining to prepare round bar specimen for TDA from the center part of the bars. They are measuring $5 \mathrm{~mm}$ in diameter and 50 $\mathrm{mm}$ in length. These specimens are subjected to cathodic hydrogen charging in $0.1 \mathrm{~N} \mathrm{H}_{2} \mathrm{SO}_{4}$ solution with 0.06 mass $\%$ $\mathrm{NH}_{4} \mathrm{SCN}$. The periods for hydrogen charging were 1 day for $45 \mathrm{~A}$ and $45 \mathrm{~B}$, and 2 days for $45 \mathrm{C}$ and $10 \mathrm{~A}$. The 1 day charging is enough to fulfill the specimens of $5 \mathrm{~mm}$ diameter. The hydrogen charged specimens are reserved in liquid nitrogen for less than 1 hour before TDA measurements. The gas chromatograph is used for hydrogen detection and the heating rate is set to $100 \mathrm{~K} / \mathrm{h}$.

\section{Experimental Results and Discussion}

\subsection{Curve Fitting by Kissinger Equation}

Figure 1 shows the results of TDA measurement on steel 45C and curve fitting by Kissinger equation. ${ }^{10)}$ Here the

Table 1. Chemical compositions of S45C and S10C steels.

\begin{tabular}{cccccccccccc}
\hline Steel & $\mathrm{C}$ & $\mathrm{Si}$ & $\mathrm{Mn}$ & $\mathrm{P}$ & $\mathrm{S}$ & $\mathrm{Cu}$ & $\mathrm{Ni}$ & $\mathrm{Cr}$ & $\mathrm{Mo}$ & $\mathrm{Al}$ & $\mathrm{N}$ \\
\hline 45A & 0.46 & 0.21 & 0.74 & 0.024 & 0.023 & 0.10 & 0.04 & 0.15 & 0.01 & 0.004 & 0.0127 \\
45B & 0.46 & 0.21 & 0.81 & 0.019 & 0.019 & 0.03 & 0.01 & 0.14 & $<0.01$ & 0.033 & 0.0005 \\
45C & 0.47 & 0.19 & 0.79 & 0.017 & 0.018 & 0.01 & 0.02 & 0.19 & 0.01 & 0.024 & 0.0052 \\
$10 \mathrm{~A}$ & 0.14 & 0.20 & 0.54 & 0.014 & 0.013 & 0.10 & 0.05 & 0.06 & $<0.01$ & 0.032 & 0.0051 \\
\hline
\end{tabular}

$\mathrm{V}, \mathrm{Nb}, \mathrm{Ti}<0.01$ mass $\%$

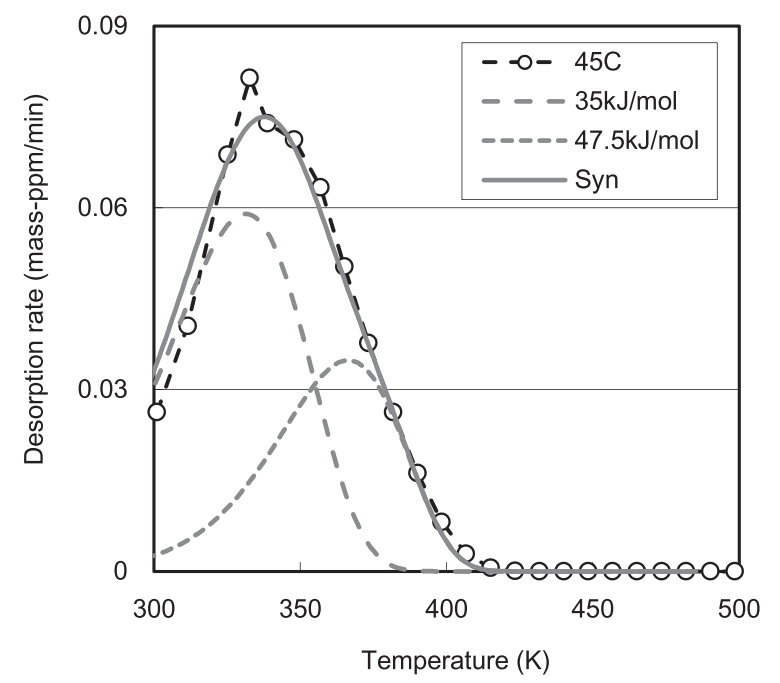

Fig. 1. Hydrogen desorption spectrum of $45 \mathrm{C}$ steel and fitting by Kissinger equation with activation energies of $35 \mathrm{~kJ} / \mathrm{mol}$ and $47.5 \mathrm{~kJ} / \mathrm{mol}$. cathodic current density was to $3 \mathrm{~A} / \mathrm{m}^{2}$.

The measured data are plotted by circle symbols. At the beginning of measurement, the specimen temperature remaining almost $300 \mathrm{~K}$, the data points below $300 \mathrm{~K}$ overlap with that at $300 \mathrm{~K}$. The measured data appear almost forming one continuous curve: The data point projects around $332 \mathrm{~K}$ and might be composed of two peaks.

The Kissinger equation expresses the amount of reaction during heating at constant rate. It is applied to hydrogen desorption by Wei and Tsuzaki ${ }^{16)}$ for hydrogen desorption from ferrite matrix containing $\mathrm{TiC}$ precipitate as trapping sites. It is expressed as follows;

$$
\frac{d X}{d t}=A(1-X) \exp \left(-\frac{E_{B}}{R T}\right)
$$

Here $\mathrm{X}$ is proportion of desorbed hydrogen, $\mathrm{t}$ is time and $\mathrm{A}$ is the pre-exponent constant, $E_{B}$ is the activation energy for reaction, $\mathrm{R}$ is gas constant and $\mathrm{T}$ is temperature. As it contains only two explanatory variables, so it is less arbitrary than the case of McNabb-Foster ${ }^{7-9)}$ equation, and seems more admissible for describing desorption curve. The desorption curve can be numerically calculated using Eq. (2), which is the differential form of Eq. (1). The suffixes $\mathrm{n}-1$ and $\mathrm{n}$ means subsequent former and following steps.

$$
\frac{\Delta X_{n}}{\Delta t}=A\left(1-X_{n-1}\right) \exp \left(-\frac{E_{B}}{R T_{n-1}}\right) .
$$

Kissinger equation is normally available where hydrogen desorption is rate controlled only by de-trapping. So it is more suitable for desorption from smaller specimens of pure iron or carbon steel. ${ }^{17)}$

Considering the ideal situation for the use of Kissinger equation, trials have been made to approximate the measured data points by the use of one or two Kissinger curves, where the activation energies are varied from 30 to $50 \mathrm{~kJ} / \mathrm{mol}$ at $2.5 \mathrm{~kJ} / \mathrm{mol}$ intervals. The approximation by one curve is not successful. Superimpose of desorption curves from two kinds of traps, whose activation energies are 35 and $47.5 \mathrm{~kJ} / \mathrm{mol}$, can be rationalized. The result is shown in Fig. 1 by dotted lines. The solid line (Syn) shows the synthesis of them. Desorption curve by Kissinger equation is less arbitrary; the shape and position of the peak are restricted. In this situation, the curve fitting in Fig. 1 is almost satisfactory.

The important point of the description so far is that curve fitting is conducted fairy well by the synthesis of two desorption curves. It is based on the assumption of fast enough diffusion of hydrogen in lattice. Fitting by two desorption curves is also confirmed in SCM435 steel, ${ }^{18)}$ whose chemical composition and microstructure are different. This can be a certain part of the verification of hypothesis. Further verification will be done through confirmation of availability in the latter sections, especially sections 3.4 and 3.5.

Usually desorption curves of pure iron or carbon steel appears one peak and the hydrogen is believed to be trapped mainly by dislocation ${ }^{17,19)}$ i.e. elastic strain field of edge dislocation. The main peak around $330 \mathrm{~K}$, which is almost equal to the temperature of maximum desorption is due to dislocation trap. Although desorption curve by Kissinger equation is dependent on both activation energy $\mathrm{E}_{\mathrm{B}}$ and preexponent coefficient A, the applied activation energy fortunately falls within the range of suravey. ${ }^{20)}$ 
Hydrogen in steel can be trapped by various other lattice defects than dislocation. In case of carbon steels, ferrite/ cementite boundary in pearlite and grain boundary could be the trapping sites. The ferrite/cementite boundary existing much in pearlite though, it is reported that hydrogen moves through this boundary faster than the diffusion in lattice. ${ }^{21)}$ It cannot be the trapping site. It is also reported that the binding energy of the ferrite/cementite boundary is as low as $19 \mathrm{~kJ} / \mathrm{mol} . ;^{22)}$ the boundary is judged hardly to be the hydrogen trap. According to Hirth ${ }^{23)}$ binding energy of hydrogen with grain boundary is up to $58.6 \mathrm{~kJ} / \mathrm{mol}$, although it changes depending on the structure of grain boundary. Ono and Meshii ${ }^{24)}$ have reported that $49 \mathrm{~kJ} / \mathrm{mol}$ for polycrystalline pure iron. Thus, grain boundary could be stronger trap site than dislocation. As this binding energy is not so large as $94.6 \mathrm{~kJ} / \mathrm{mol}^{25)}$ of $\mathrm{TiC} /$ ferrite boundary, its own peak is not observed separately. This may be the reason why grain boundary has not long been acknowledged as trapping site. This newly separated hydrogen trap is sure to agree with grain boundary.

\subsection{Discrepancy between Estimation and Measurement}

The curve fitting is fairly good in Fig. 1. It is still susceptible to some improvements, though. The previous report ${ }^{18)}$ treated the same kind of dissatisfaction. It is attributed to the effect of carrier gas flow; a mixed-up volume should change the shape of desorption curve.

Among other factors that cause the shape change, nonhomogeneity of trap site can be pointed out. Generally a kind of trap site is considered uniform; namely unique values of $A$ and $E_{B}$ in Eq. (1). Actually for an example of dislocation, $\mathrm{E}_{\mathrm{B}}$ varies depending on the distance from dislocation core. ${ }^{20,23)}$ Values of $A$ and $E_{B}$ are not unique and distributed around certain values. Measured desorption curve receives a kind of integration depending on these distributions of $\mathrm{A}$ and $\mathrm{E}_{\mathrm{B}}$.

Figure 2 illustrates a simple example of this integration. A desorption curve is selected that is obtained from Kissinger equation with $A$ and $E_{B}$ are 3000 and $47.5 \mathrm{~kJ} / \mathrm{mol}$ respectively. Variation is given by shifting temperature. In this case, integration is easily conducted by averaging the des-

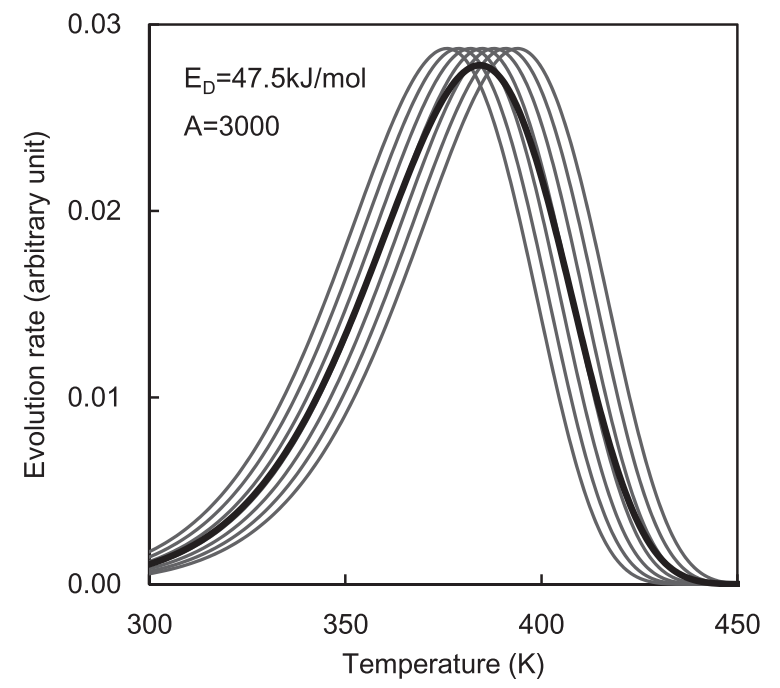

Fig. 2. Deformation of desorption spectrum in the case of multiple trapping sites. orption rate for each temperature. Thick line represents the results. It differs from the elemental curves of thin lines: The slope of higher temperature side turns gentle and the shape rather approaches to symmetrical form.

Another factor that would cause the shape change is the non-homogeneity in temperature, such as inevitable temperature gradient along axis. This non-homogeneity can be also expressed by thin curves in Fig. 2. The thin curve shifts more to the left side at higher temperature portion. The overall desorption curve becomes like the thick curve, showing the shape change toward symmetrical one.

This integration or averaging of uncertainties, which are just the same with the above-mentioned flow mixed-up volume, has the effect of making the slope gentle at higher temperature side. All these non-homogeneity will allow the measured desorption curves fitted by symmetrical Gaussian distribution; Gaussian is a reasonable tool for analyzing the measurement.

Figure 3 illustrates the curve fitting by Gaussian. As discussed before, curve A1 is for the hydrogen trapped by dislocation and curve A2 corresponds to hydrogen trapped by grain boundary. The fitness is excellent and the peak temperature of $\mathrm{A} 1$ or $\mathrm{A} 2$, which is important to determine the kind of trap, is almost same with the fitting by Kissinger equation as shown in Fig. 1. One can understand the availability of fitting by Gaussian.

Gaussian has been applied to the analysis of TDS desorption curves. ${ }^{11,26)}$ Their measured curves were well separated or had already separated tops. In contrast, present separation works for continuous and smooth desorption curves.

\subsection{Heat to Heat Variation of Hydrogen Desorption}

Figure 4 compares hydrogen desorption behavior between steels $45 \mathrm{~A}$ and $45 \mathrm{~B} .{ }^{13)}$ These two steels are cathodically charged at current densities of 1.7 and $20 \mathrm{~A} / \mathrm{m}^{2}$ for 1 day. They are fitted by two Gaussian and the parameters, i.e. peak temperature, peak height and peak width (standard deviation, SD) are summarized in Table 2.

The increase in current density makes the peak height increased, but the SD is not affected. On the other hand, comparing steels, difference in peak temperature attracts attention. Peak temperature of $\mathrm{A} 2$ is almost $10 \mathrm{~K}$ higher in

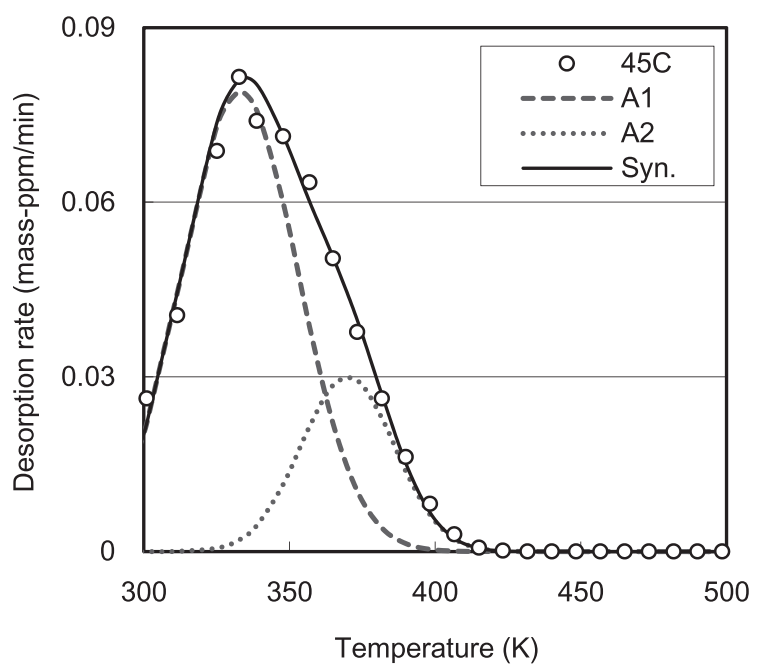

Fig. 3. Analysis of desorption spectra by Gaussian distribution. 

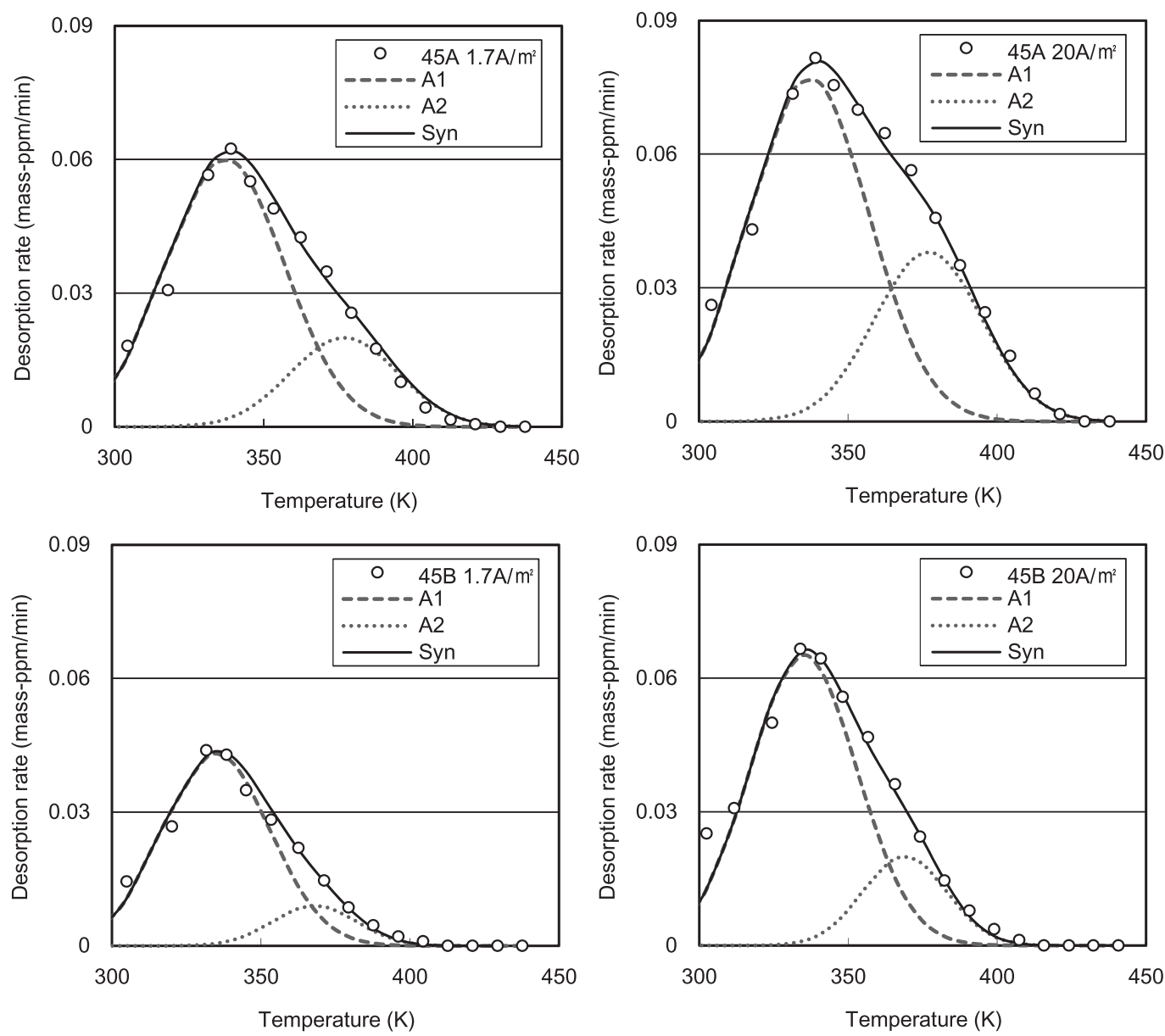

Fig. 4. Analysis of desorption spectrum by Gaussian distribution. Two kinds of normalized S45C steels (45A and 45B) are hydrogen charged at two different current densities.

Table 2. Summary of fitting for heat to heat variation in S45C steels.

\begin{tabular}{clcccc}
\hline \multirow{2}{*}{ Peak } & \multicolumn{1}{c}{ Item } & \multicolumn{2}{c}{$45 \mathrm{~A}$} & \multicolumn{2}{c}{$45 \mathrm{~B}$} \\
\cline { 3 - 6 } & & $1.7 \mathrm{~A} / \mathrm{m}^{2}$ & $20 \mathrm{~A} / \mathrm{m}^{2}$ & $1.7 \mathrm{~A} / \mathrm{m}^{2}$ & $20 \mathrm{~A} / \mathrm{m}^{2}$ \\
\hline \multirow{2}{*}{ A1 } & Height, ppm/min & 0.06 & 0.077 & 0.043 & 0.065 \\
& Width (SD) K & 20 & 20 & 18 & 18 \\
& Temp. K & 337 & 337 & 335 & 335 \\
\hline \multirow{2}{*}{ A2 } & Height, ppm/min & 0.02 & 0.038 & 0.009 & 0.02 \\
& Width (SD) K & 18 & 18 & 14 & 14 \\
\hline Peak height ratio (A"/A1) & 0.33 & 0.49 & 0.21 & 0.31 \\
\hline
\end{tabular}

steel $45 \mathrm{~A}$ than that of steel $45 \mathrm{~B}$. Further peak height ratio (A2/A1) is larger in steel $45 \mathrm{~A}$ than steel $45 \mathrm{~B}$, suggesting the hydrogen in $45 \mathrm{~A}$ steel is strongly bound by grain boundary. The 45A steel contains more phosphorous and it is believed to segregating along grain boundary. It can be deduced that phosphorous segregation enhances the binding energy between hydrogen and grain boundary.

\subsection{Effect of Current Density on Hydrogen Trapping}

Normalized steel $10 \mathrm{~A}^{15)}$ is hydrogen charged at cathodic current densities between 20 to $100 \mathrm{~A} / \mathrm{m}^{2}$ for 2 days. The obtained hydrogen desorption curves are also fitted with two Gaussian distribution curves. The parameters (peak temper-
Table 3. Summary of fitting for S10C hydrogen charged with different current densities.

\begin{tabular}{|c|c|c|c|c|c|c|c|}
\hline \multirow{2}{*}{ Peak } & \multirow{2}{*}{ Item } & \multicolumn{6}{|c|}{ Current density $\left(\mathrm{A} / \mathrm{m}^{2}\right)$} \\
\hline & & $2 \mathrm{~A} / \mathrm{m}^{2}$ & $5 \mathrm{~A} / \mathrm{m}^{2}$ & $10 \mathrm{~A} / \mathrm{m}^{2}$ & $20 \mathrm{~A} / \mathrm{m}$ & $50 \mathrm{~A} / \mathrm{m}^{2}$ & $100 \mathrm{~A} / \mathrm{m}^{2}$ \\
\hline \multirow{3}{*}{ A1 } & Height, $\mathrm{ppm} / \mathrm{min}$ & 0.025 & 0.0252 & 0.028 & 0.031 & 0.033 & 0.034 \\
\hline & Width (SD) K & 332 & 332 & 332 & 332 & 332 & 332 \\
\hline & Temp. K & 21 & 21 & 21 & 21 & 21 & 21 \\
\hline \multirow{3}{*}{$\mathrm{A} 2$} & Height, $\mathrm{ppm} / \mathrm{min}$ & 0.0065 & 0.0074 & 0.0085 & 0.0100 & 0.0110 & 0.0130 \\
\hline & Width (SD) K & 367 & 367 & 367 & 367 & 367 & 367 \\
\hline & Temp. K & 12 & 12 & 12 & 12 & 12 & 12 \\
\hline \multicolumn{2}{|c|}{$\begin{array}{c}\text { Peak height ratio } \\
\text { (A"/A1) }\end{array}$} & 0.260 & 0.292 & 0.304 & 0.323 & 0.333 & 0.382 \\
\hline
\end{tabular}

ature, peak height and peak width are summarized in Table 3. While fitting, peak height and peak width (SD) are set $332 \mathrm{~K}$ and $21 \mathrm{~K}$ for $\mathrm{A} 1$ peak, and $367 \mathrm{~K}$ and $12 \mathrm{~K}$ for $\mathrm{A} 2$ peak. The results of fitting are shown in Fig. 5. In spite of the wide range of current densities, fitting is fairly well conducted. In addition, when the current density is as high as $100 \mathrm{~A} / \mathrm{m}^{2}$, the curve trails its skirt beyond $400 \mathrm{~K}$; it surpasses the synthesis (Syn) of peaks A1 and A2 there. It is reported that the low carbon steel, when it is severely hydrogen charged, suffers formation of blisters or cracks. ${ }^{27)}$ The trailed skirts may suggest blister formation.

The heights of peaks A1 and A2 are plotted against cur- 

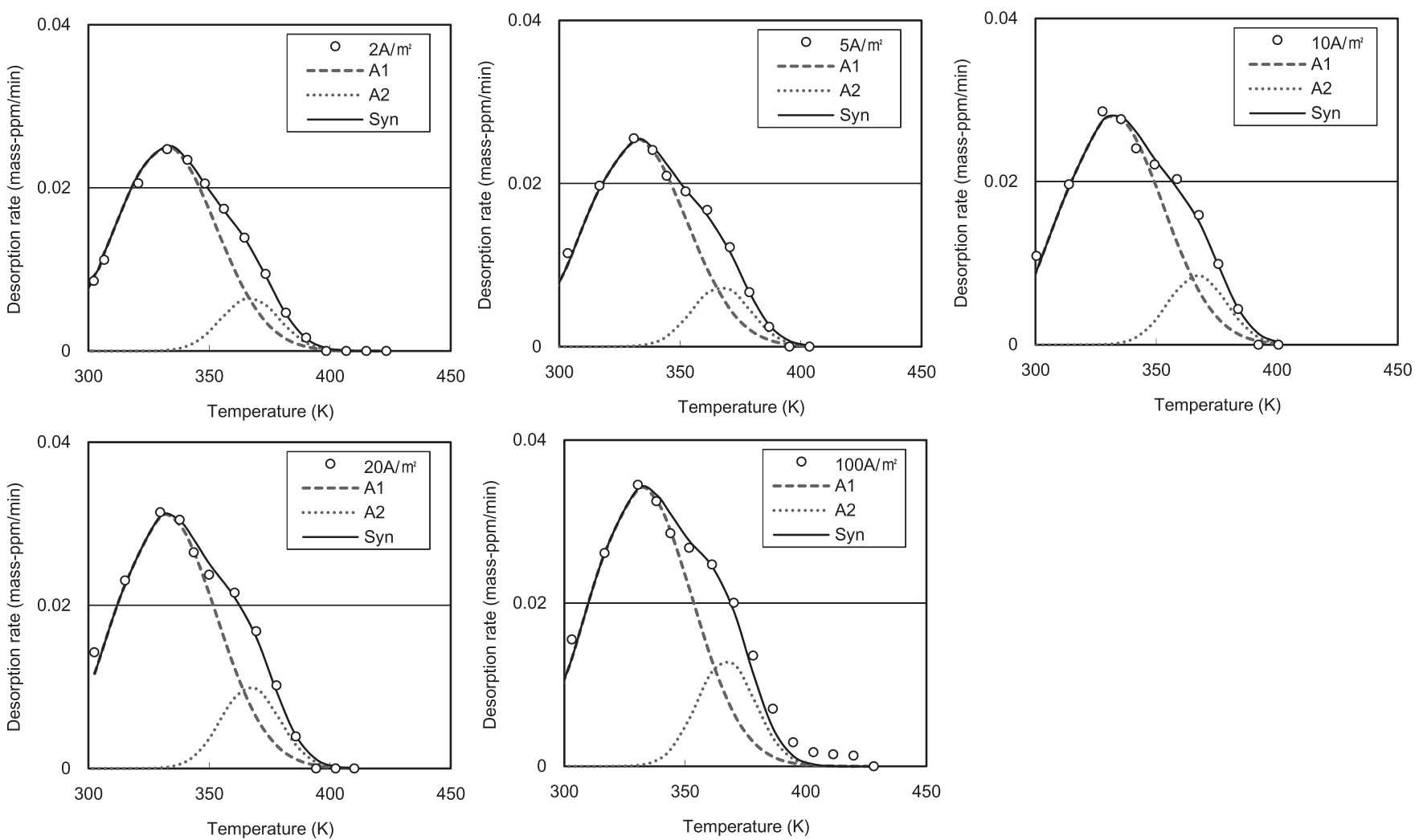

Fig. 5. Analysis of desorption spectrum by Gaussian distribution. 10A steel is hydrogen charged at different current densities.

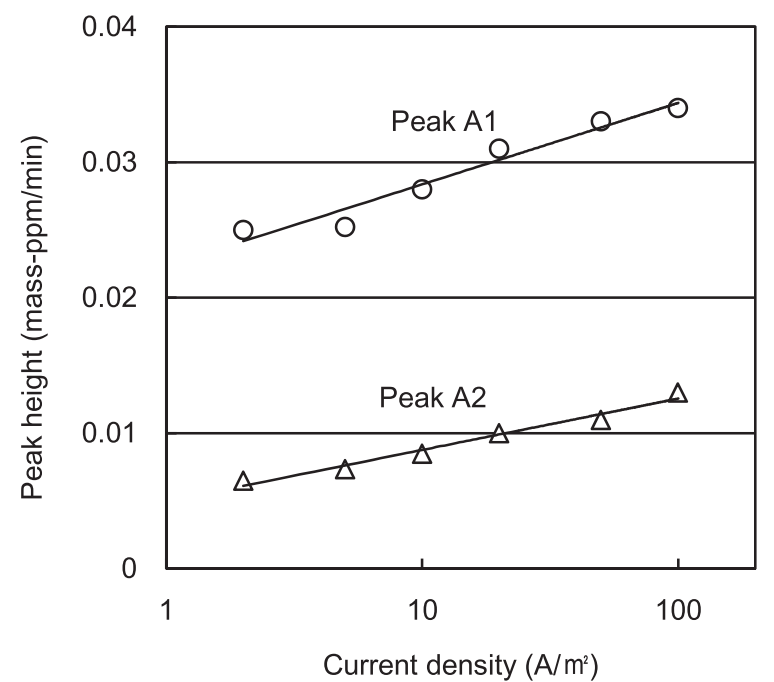

Fig. 6. Increase of peak height by current density. A1 and A2 are for dislocation trap and grain boundary trap respectively.

rent densities in Fig. 6. They increase with logarithm of current density, but the slope is different. Figure 7 shows the relation between peak height ratio (A2/A1) and current density. The ratio increases with current density, meaning increased hydrogen partitioning to grain boundary.

As discussed in Fig. 2, trap site is not homogeneous. As the hydrogen charging potential rises, hydrogen becomes trapped where energetic benefit is smaller. This results in the decreased increment of hydrogen trap. Figure 2 also suggests that larger non-homogeneity makes widely distributed desorption curve. Peak width (SD) of dislocation trap is wider than grain boundary trap, as shown in Tables 2 or 3 .

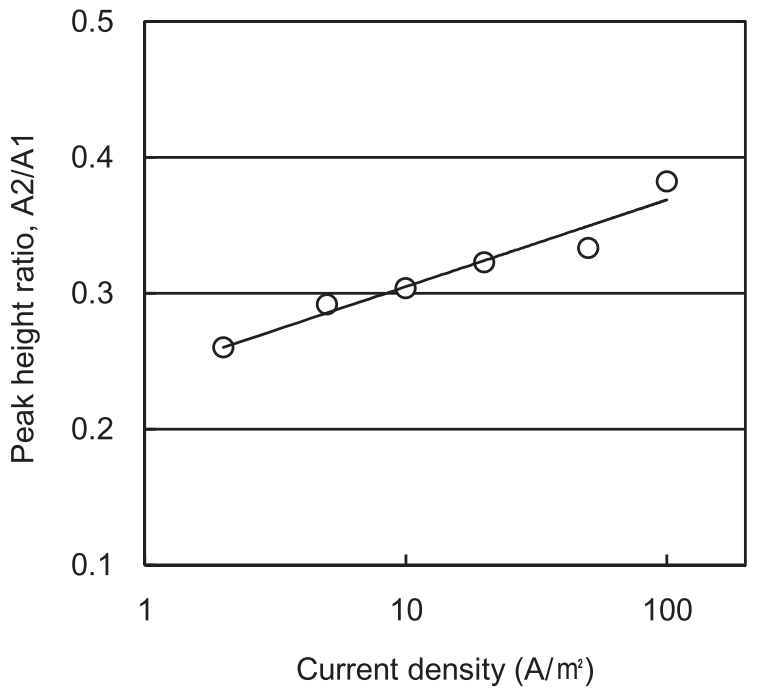

Fig. 7. Increase of peak height ratio by current densities. Increase of A2/A1 shows that more hydrogen is distributed to grain boundary.

When the current density is increased, hydrogen increment at dislocation trap tends to decrease, leading to decreased hydrogen partition to dislocation and increased partition to grain boundary.

\section{Summary}

For the basis of understanding hydrogen embrittlement in normalized carbon steels that are composed of ferrite and pearlite, hydrogen thermal desorption curves are analyzed for making clear the kinds and amounts of traps sites. 
Supposing that the diffusion rate of soluble hydrogen is fairly large and hydrogen desorption is rate controlled by detrapping from the hydrogen traps, Kissinger equation may be applied to curve fitting. The desorption curve obtained for normalized JIS S45C are successfully fitted with two curves based on the Kissinger equation: One is corresponding to the hydrogen that was trapped by elastic strain field around dislocation, and the other is that trapped by grain boundary.

Further, through the consideration into the variation of trapping energy in the steels or possible temperature gradient along specimen axis, it was revealed that those nonhomogeneities make the measured desorption curves deformed; the curves come close to Gaussian distribution. Substitution of fitting curves from Kissinger type to Gaussian type is advantageous in practicing curve fitting.

This method was applied to the hydrogen desorption curves of different carbon steels under different charging condition. It revealed that phosphorus ingredient causes increased amount of hydrogen along grain boundary. It is also shown that increased cathodic current density causes more hydrogen partition to grain boundary.

\section{REFERNCES}

1) J. P. Laurent and G. Lappaset: Int. J. Appl. Radiat., 24 (1973), 213.

2) J. Ovejero-Garcia: J. Mater. Sci., 80 (1985), 2623.

3) K. Sakaki, T. Yamada, M. Mizuno, H. Araki and Y. Shirai: Mater.
Trans., 43 (2002), 2662.

4) I. Maroef, D. L. Olsen, M. Eberhart and G. R. Edwards: Int. Mater. Rev., 47 (2002), 191.

5) K. Takai: Trans. Jpn. Soc. Mech. Eng., A70 (2004), 9.

6) M. Fujinami, Y. Kawashima, K. Yanagi, S. Jinno, M. Uchikoshi, M. Isshiki and S. Suzuki: Tetsu-to-Hagané, 97 (2011), 266.

7) A. McNabb and P. K. Foster: Trans. Metall. Soc., AIME, 227 (1963), 618.

8) K. Ebihara, H. Kaburaki, T. Suzudo and K. Takai: ISIJ Int., 49 (2009), 1907

9) M. Enomoto, D. Hirakami and T. Tarui: ISIJ Int., 46 (2006), 1381.

10) H. E. Kissinger: Anal. Chem., 29 (1957), 1702.

11) T. Yokota and T. Shiraga: ISIJ Int., 43 (2003), 534.

12) Y. Fujita, Y. Sato, H. Suzuki, K. Takai and Y. Hagihara: CAMP-ISIJ, 21 (2008), 1376

13) G. Suzuki, K. Oishi, A. Kato, K. Tokuno and Y. Tsuchida: Tetsu-toHagané, 98 (2012), 497.

14) G. Suzuki, R. Hosoe, A. Fujita and Y. Tsuchida: J. Japan Soc. Heat Treat., $\mathbf{5 2}$ (2012), 269.

15) T. Yamashita, K. Honda, F. Fujisawa and Y. Tsuchida: JHPT, 48 (2010), 11

16) F. G. Wei and K. Tsuzaki: Metall. Mater. Trans. A, 37A (2006), 331.

17) K. Ebihara, T. Suzudo, H. Kaburaki, K. Takai and S. Takebayashi: Tetsu-to-Hagané, 94 (2008), 522.

18) Y. Tsuchida: J. High Pressure Inst., to be published.

19) K. Takai, G. Yamauchi, M. Nakamura and M. Nagumo: J. Jpn. Inst. Met., 62 (1998), 267.

20) M. Enomoto, D. Hirakami and T. Tarui: Metall. Mater. Trans. A, 43A (2012), 572.

21) K. Ichitani: ISIJ Int., 43 (2003), 496.

22) K. Takai: Trans. Jpn. Soc. Mech. Eng. A, 70 (2004), 1027.

23) J. P. Hirth: Metall. Trans. A, 11A (1980), 861.

24) K. Ono and M. Meshii: Acta Metall. Mater., 40 (1992), 1357.

25) G. M. Pressouyre and I. M. Bernstein: Metall. Trans. A, 9A (1978), 1571.

26) T. Izumi and G. Itoh: Mater. Trans., 52 (2011), 130.

27) H. Hagi: J. Jpn. Inst. Met., 61 (1997), 274. 